\title{
ANALOG SIGNAL RECORDER
}

\author{
R. J. SAND
}
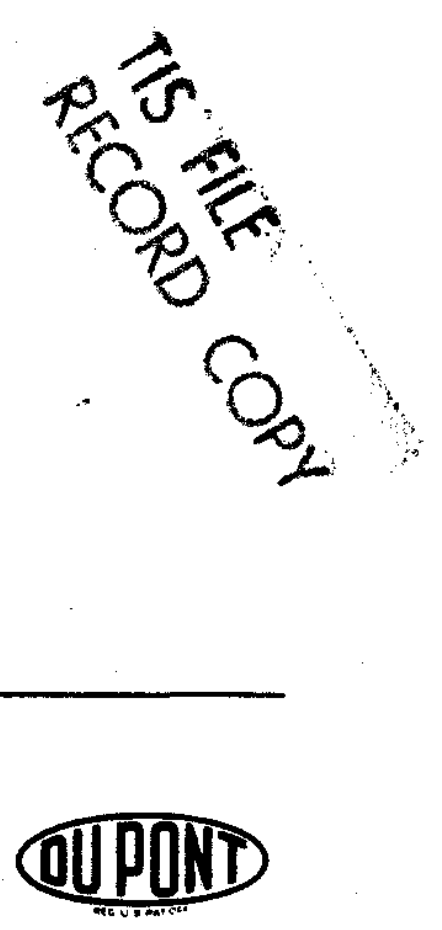

\section{SAVANNAH RIVER LABORATORY AIKEN, SOUTH CAROLINA 29801}

PREPARED FOR THE U.S. ENERGY RESEARCH AND DEVELOPMENT ADMINISTAATION UNDER CONTRACT AT(07-2) -1 
(1)

\section{NOTICE}

This report was prepared as an account of work sponsored by the United States Government. Neither the United States nor the United States Energy Research and Development Administration, nor any of their contractors, subcontractors, or their empioyes, makes any warranty, express or implied, or assumes any legal liability or responsibility for the accuracy, completeness or usefulness of any information, apparatus, product or process disclosed, or represents that its use would not infringe privately owned rights.

Printed in the United States of America

Availabie from

National Technical Information Service

U. S. Department of Commerce

5285 Port Royal Road

Springfield, Virginia 22161

Price: Printed Copy \$4.00; Microfiche \$2.25 
DP-1379

Distribution Category: UC-37

\section{ANALOG SIGNAL RECORDER}

by

R. J. Sand

Approved by

D. E. Waters, Manager

Laboratory Operations and Services Division

Publication Date: October 1975

E. I. DU PONT DE NEMOURS AND COMPANY SAVANNAH RIVER LABORATORY AIKEN, SOUTH CAROLINA 29801 
An analog signal recorder was designed and built by interfacing an audio cassette tape recorder with input frequency modulators for converting the signal for tape storage and with output frequency demodulators that reconstruct the signal for data sampling. The system is inexpensive, portable, and versatile. Full-scale input ranges are 0 to $50 \mathrm{mV}, 0$ to $100 \mathrm{mV}, 0$ to $1 \mathrm{~V}$, or 0 to $10 \mathrm{~V}$; output is 0 to $\pm 10 \mathrm{~V}$. Frequency response is between 0 and $10 \mathrm{~Hz}$. 


\section{CONTENTS}

Introduction 5

Signal Recorder General Description 5

Circuit Description 6

\section{LIST OF FIGURES}

1 Analog Signal Recorder 7

2 System Block Diagram of Analog Signal Recorder 8

3 Block Diagram of ASR Frequency Modulator, Left Channel 8

4 Transfer Characteristics of Modulator Amplifiers $A$ and $B$

9

5 Actual Operating Curve for Voltage-Controlled Oscillator 9

6 Effective Curve for the Frequency Modulator 10

7 Block Diagram of ASR Frequency Demodulator 10

8 Transfer Characteristics of Frequency-to-Voltage Converter

9 Output Range of Inverting Operational Amplifier Y 11

10 Overall System Transfer Characteristics 12

11 ASR Frequency Response 12 
ANALOG SIGNAL RECORDER

\section{INTRODUCTION}

The capability to record test signals for later playback is a frequent requirement in research work. Large data sampling systems are generally too bulky to be moved around easily and often will not conveniently fit in areas used for tests. The Analog Signal Recorder described in this report is portable and utilizes a small audio cassette tape deck to record and reproduce the actual analog signal. Appropriate analog interface circuitry enables the recording and playback of the signal so that recorded information can be retrieved by a data sampling system as needed to provide input to data analysis systems.

\section{SIGNAL RECORDER GENERAL DESCRIPTION}

The analog signal recorder (ASR) is basically an audio 'tape recorder with proper electronics to condition both input and output signals (Figure 1). Since audio recorders have low frequency cutoff in the range of 20 to $30 \mathrm{~Hz}$, recording an analog voltage with a frequency content of 0 to $10 \mathrm{~Hz}$ requires some signal conditioning. Frequency modulation enables these DC and low-frequency signals to be recorded. The ASR is built around a stereo tape deck and contains two sets of analog interfacing circuitry, one for each stereo channel (Figure 2). One channel (designated "Left") is modified to either accept an external analog input or to internally insert one of 20 fixed levels for use as an identification channe1. This enables positive identification of the tape during playback. This feature can also be used to identify segments of one tape as needed by a particular experiment. If voice identification of a tape or segment of a tape is desired, a microphone is plugged into the tape deck. This provides the ability to record a running account of an experiment, noting many parameters by visual interface while recording for analysis a particular electrical signal. Frequency demodulation of tape deck output provides a signal that is usable by data sampling systems. For recording over periods of time longer than those available on standard cassettes, a reel-to-reel tape deck could be used. At $1-7 / 8$ inches per second, more than 6 hours of data could be recorded on a 7-1/2-inch reel of tape. 


\section{CIRCUIT DESCRIPTION}

The input to the ASR is a high-impedance instrumentation amplifier to allow signal pickup without adverse loading effects. The range selector switch changes the gain-determining resistance in Amplifier Module A (see Figure 3) ro permit input ranges of 0 to $50 \mathrm{mV}, 0$ to $100 \mathrm{mV}, 0$ to $1 \mathrm{~V}$, and 0 to $10 \mathrm{~V}$. The output of this amplifier is 0 to $10 \mathrm{~V}$ to provide proper control of the voltage-controlled oscillator (VCO), which generates the frequency modulated signal (see Figure 4a).

Because the VCO operates on the basis of decreasing frequency for increasing voltage (referenced to ground), some manipulation of the voltage $V_{A}$ is necessary. An inverting operational amplifier Module B gives the proper slope (Figure 4b) for the operation curve, and this same operational amplifier used as a summing amplifier adds $15 \mathrm{~V}$ to produce the correct absolute curve (Figure $4 \mathrm{c}$ ).

From $B$ the signa1 $V_{B}$ goes to the VCO Module $C$, which, according to the actual operating curve (Figure 5), arrives at an effective curve (Figure 6) for the frequency modulator (Figure 3). This effective curve characterizes the frequency applied to the tape recorder after being buffered by the operational amplifier, Module $D$, producing frequency $F_{D}$. Module $D$ also removes, by the summing technique, the DC offset at the output of VCO Module C. The two-channel capability of the tape recorder establishes a two-channel analog-to-FM converter. In one channel, however, a switch enables switching from Module $A_{1}$ as an input to the identification section $A_{2} . A_{2}$ is made of a resistor string for picking off a constant voltage level. This merely replaces $\mathrm{V}_{\mathrm{A}_{1}}$ as an input and applies $\mathrm{V}_{\mathrm{A}_{2}}$.

The frequency-demodulating section consists of only three modules (Figure 7). The recorder preamp output is fed directly to Module $X$, a frequency-to-voltage converter with transfer characteristics shown in Figure $8 . V_{X}$ requires amplification to duplicate original input $\mathrm{V}_{\mathrm{I}}$. Inverting operational amplifier Module $Y$ amplifies $V_{X}$ to provide a full $10 \mathrm{~V}$ output range (Figure 9). Module $Y$ operating as a summing amplifier enables the frequency demodulator to drive a data system with positive and negative capability to obtain full input range accuracy by inserting an appropriate offset to $V_{X}$.

The inverting characteristic of Module $\mathrm{Y}$ required Module $\mathrm{Z}$ to provide the final buffered output for a system transfer characteristic shown in Figure 10. The ASR exhibits 1 inear response over its design range and will follow $10 \mathrm{~V}$ peak-to-peak singals up to $10 \mathrm{~Hz}$, as shown in Figure 11 . 

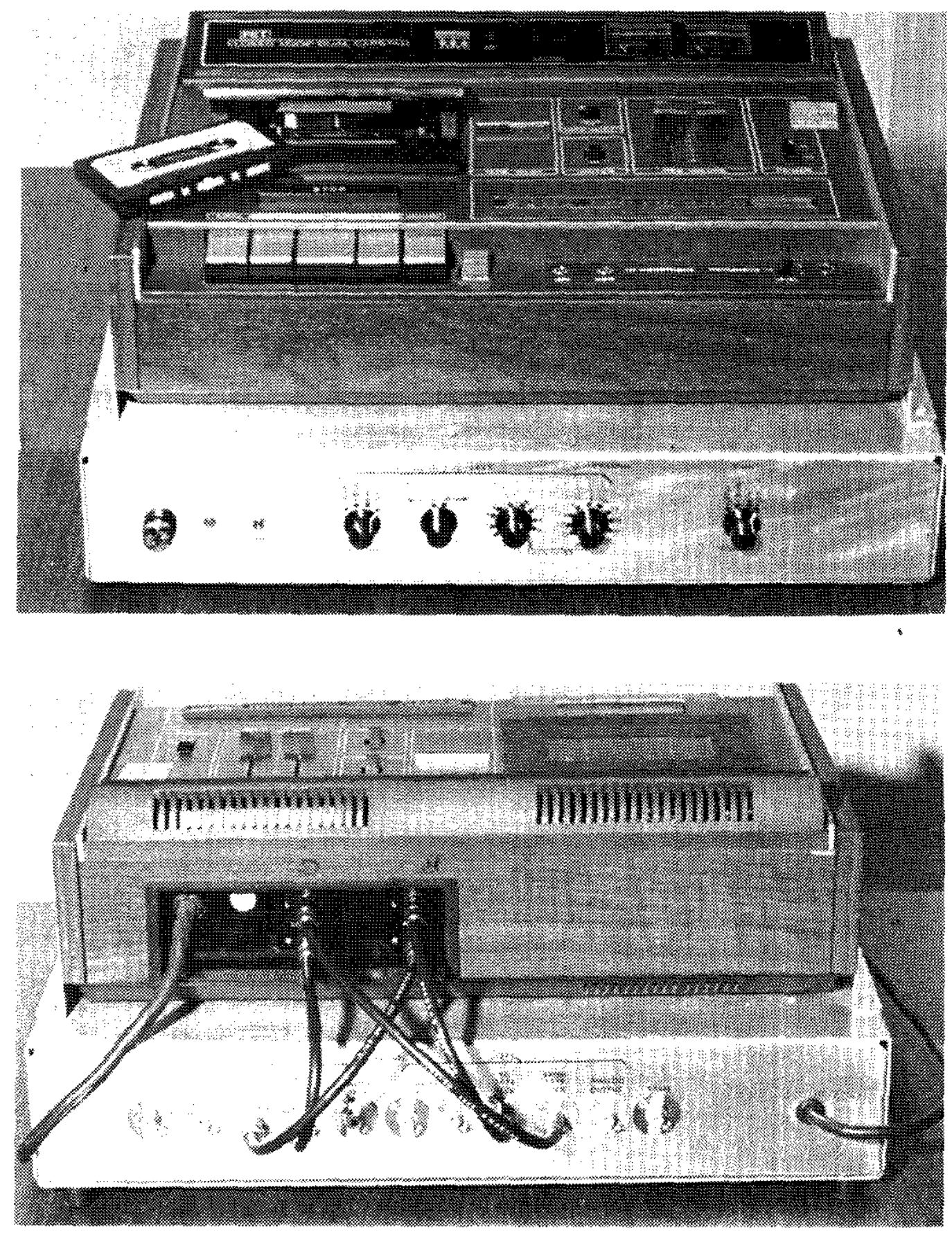

FIGURE 1. Analog Signal Recorder 


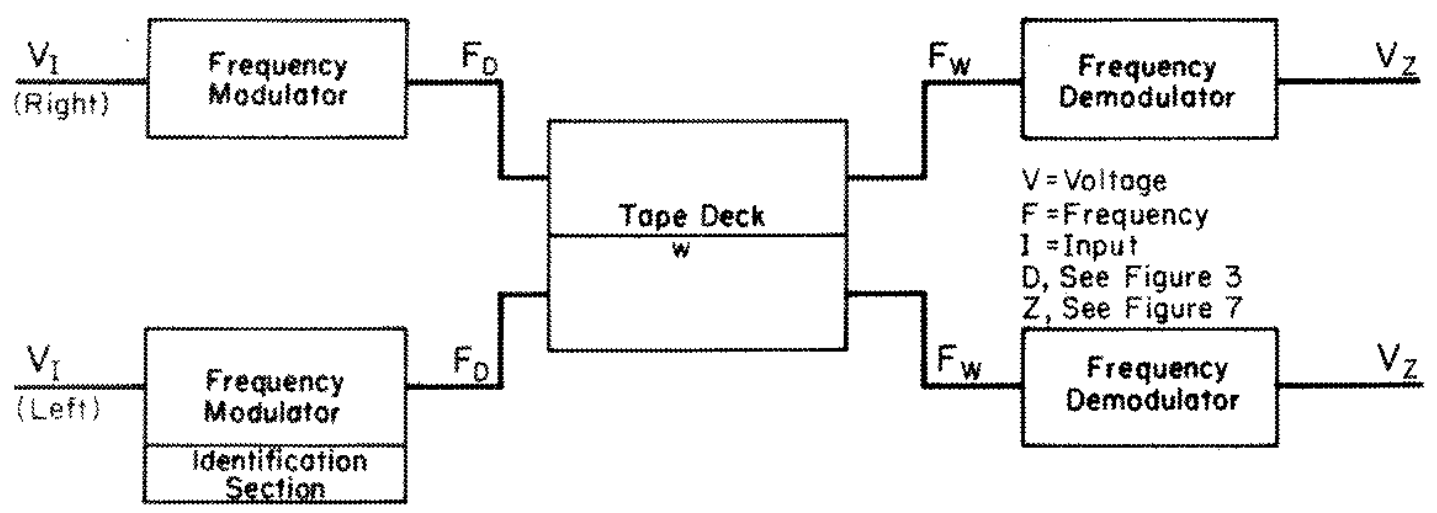

FIGURE 2. System Block Diagram of Analog Signal Recorder

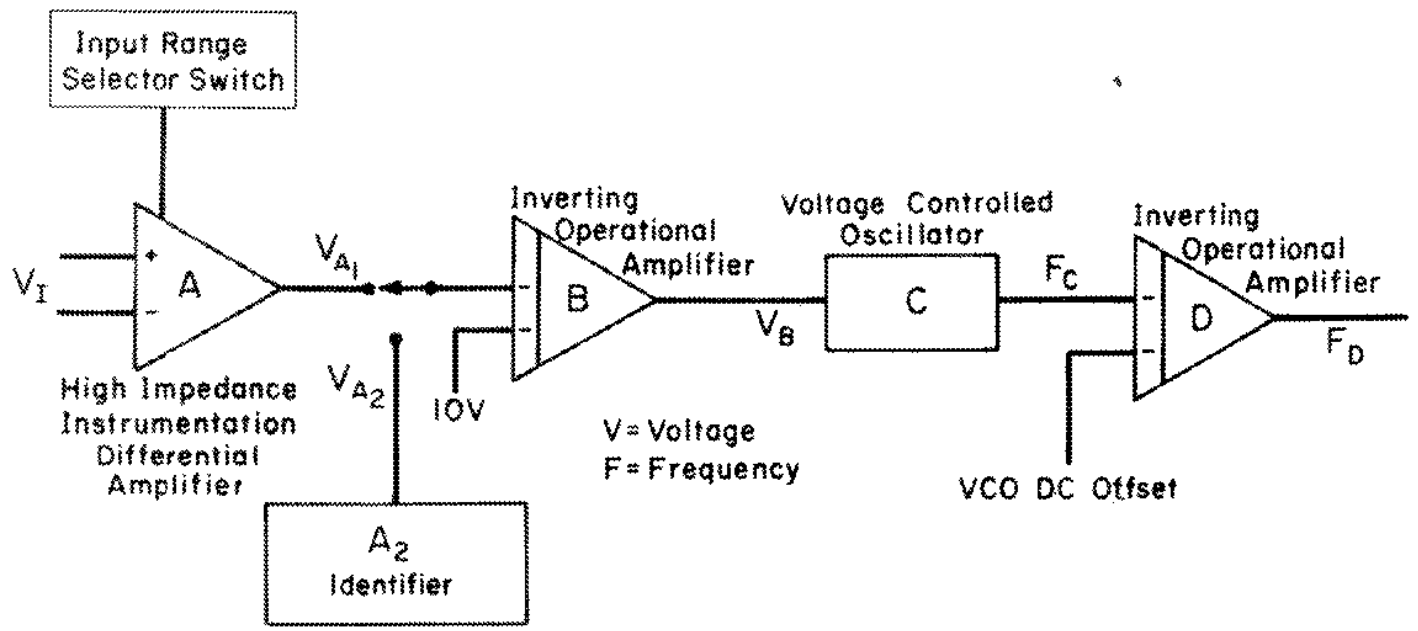

FIGURE 3. Block Diagram of ASR Frequency Modulator, Left Channel 
a.

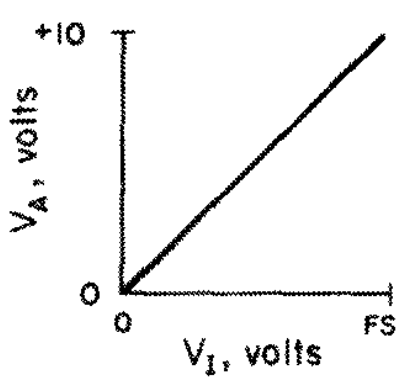

b.

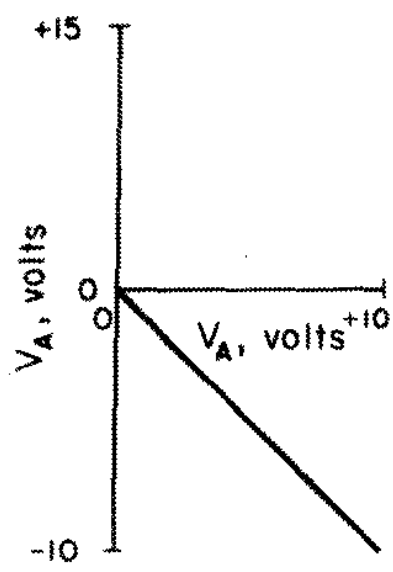

c.

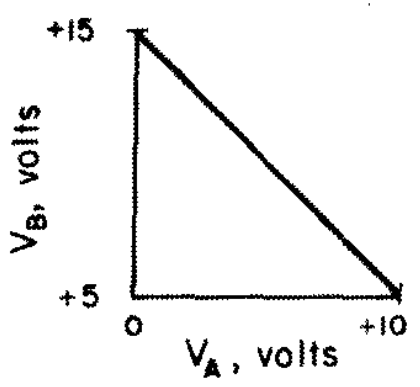

FIGURE 4. Transfer Characteristics of Modulator Amplifiers

$A$ and $B$

$V_{Y}=$ input voltage to amplifier $A$ (see Figures 2 and 3 )

$V_{A}=$ output voltage from amplifier $A$ (see Figure 3 )

$V_{B}^{A}=$ output voltage from inverting operational amplifier $B$, input to VCO (see Figure 3)

FS = full scale voltage on input range selector switch (see Figure 3)

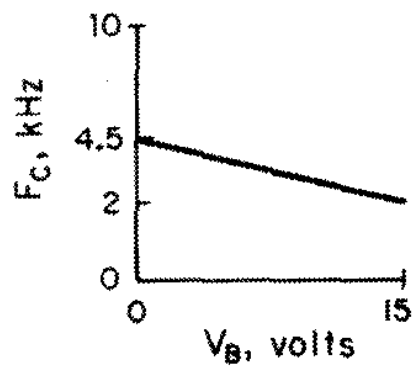

FIGURE 5. Actual Operating Curve for Voltage-Controlled

Oscillator

$F_{C}=$ frequency of VCO output (see Figure 3 )

$V_{B}^{C}=$ output voltage from inverting operational amplifier $B$ (see Figure 3 ) 


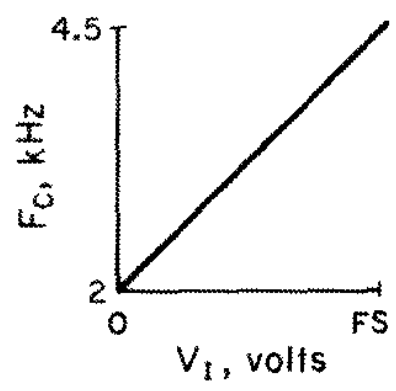

FIGURE 6. Effective Curve for the Frequency Modulator $F_{C}=$ frequency of VCO output (see Figure 3)

$V C=$ input voltage to input amplifier (see Figure 3)

FS = full scale on input range selector switch (see Figure 3 )

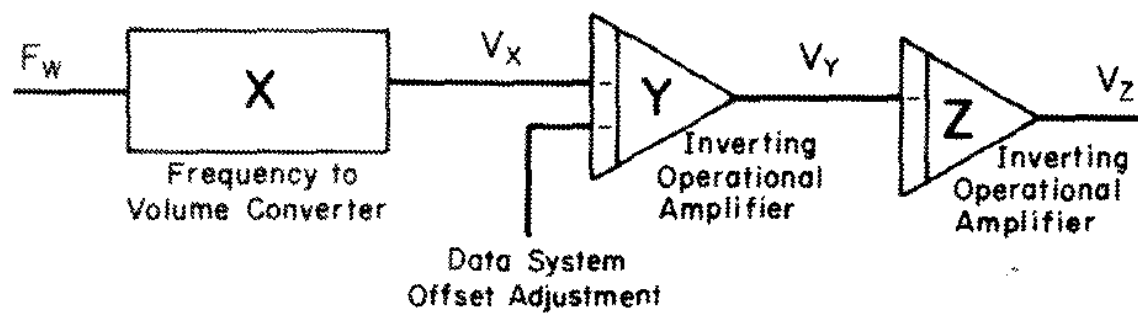

FIGURE 7. Block Diagram of ASR Frequency Demodulator

$V=$ output voltage

$F$ m frequency

$F_{W}$ m frequency of tape deck output (see Figure 2) 


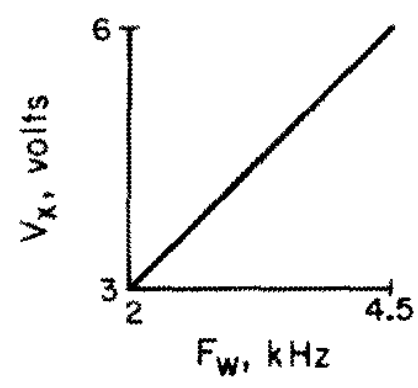

FIGURE 8. Transfer Characteristics of Frequency-to-Voltage Converter

$V_{X}=$ voltage output from frequency-to-voltage converter $X$ (see Figure 7 )

$F_{W}=$ frequency of tape deck output

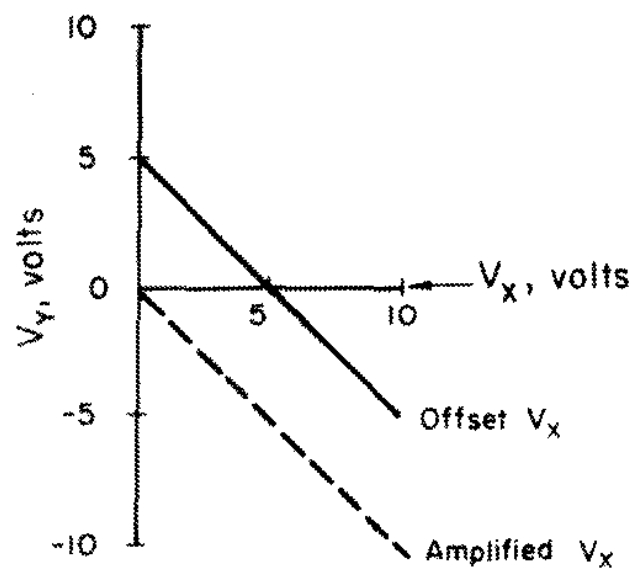

FIGURE 9. Output Range of Inverting Operational Amplifier $Y$ $V_{X}=$ voltage output of frequency-to-voltage converter $X$ (see Figure 7)

$V_{Y}=$ voltage output of inverting operational amplifier (see Figure 7 ) 


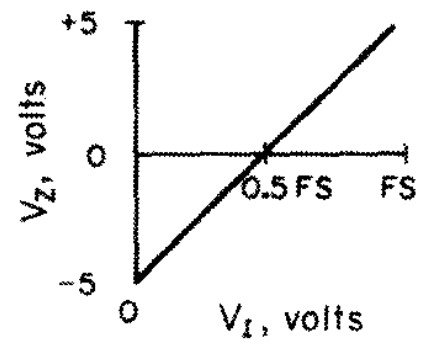

FIGURE 10. Overall System Transfer Characteristics

$V_{2}=$ voltage output from inverting operational amplifier $Z$ (see Figure 7 )

$V_{1}=$ input voltage to input amplifier A (see Figures 2 and 3)

$F S$ = full scale on input range selector switch (see Figure 3 )

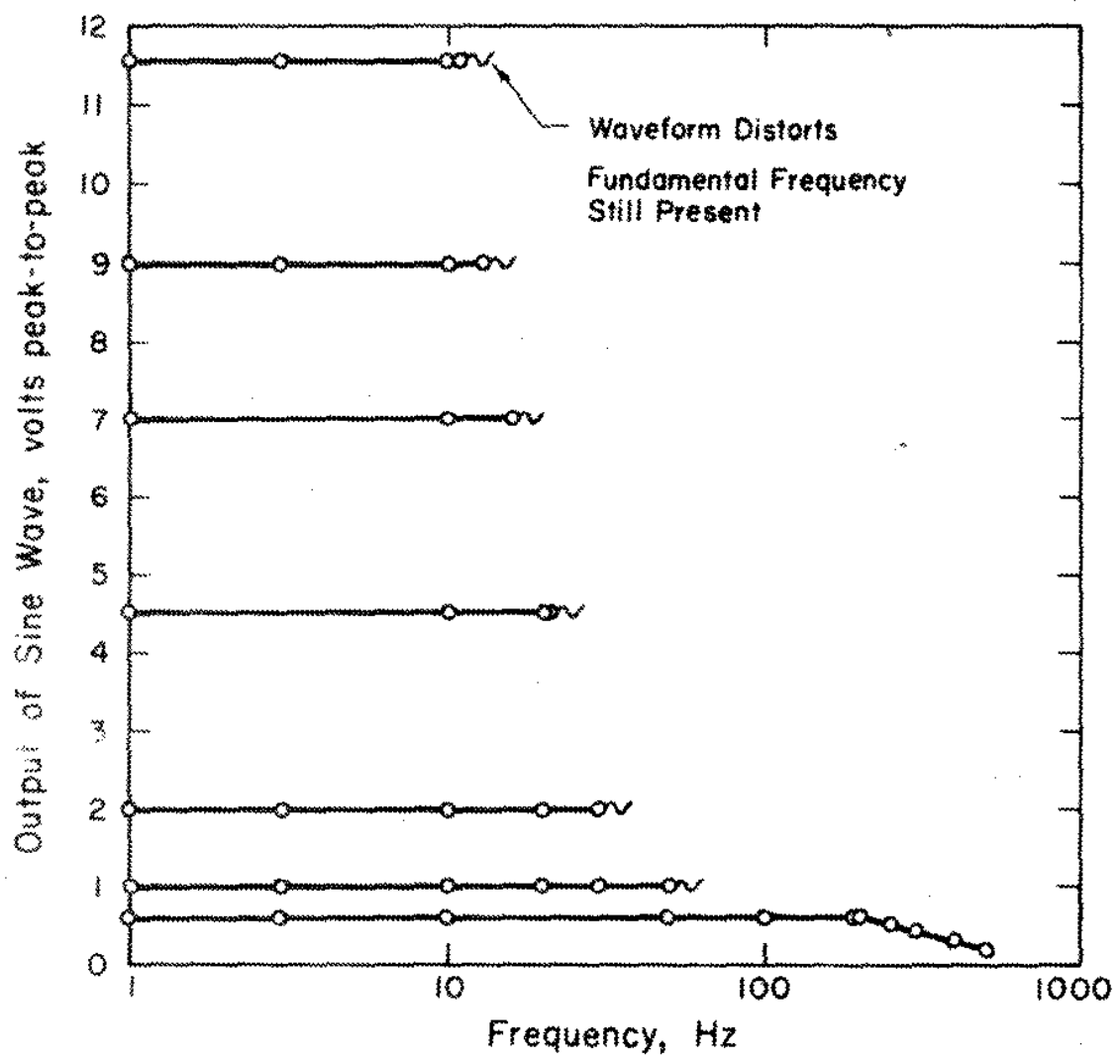

FICURE 11. ASR Frequency Response 